\title{
SINERGIA
}

REVISTA DO INSTITUTO DE CIÊNCIAS ECONÔMICAS, ADMINISTRATIVAS E CONTÁBEIS (ICEAC)

\section{ENTIDADES DO TERCEIRO SETOR: ESTUDO DE CASOS MÚLTIPLOS DA ADOÇÃO DA ITG 2002 EM PRESTAÇÕES DE CONTAS DE FUNDAÇÕES MINEIRAS DE DIREITO PRIVADO}

\author{
CRISTIANO MOREIRA SILVA \\ JOSÉ RONALDO DA SILVA \\ VICTOR HUGO PEREIRA*
}

\begin{abstract}
RESUMO
A eficiente prestação de contas é a premissa necessária para dar maior transparência a qualquer tipo de transação comercial. No que tange às instituições do terceiro setor, essa prestação tem maior significância, pelo fato de suas principais fontes de ingresso de recursos estarem atreladas a uma eficiente prestação de contas. Mediante esse contexto, a inquietação que motivou esta pesquisa foi responder ao seguinte objetivo geral: Quais são os procedimentos adotados na análise das prestações de contas das fundações de direito privado de Belo Horizonte, Minas Gerais? Em termos metodológicos, esta pesquisa se classifica como descritiva e bibliográfica. A amostra foi constituída pelas prestações de contas de cinco fundações de finalidades distintas junto à Controladoria do Centro de Apoio Operacional às Alianças Intersetoriais do Ministério Público de Minas Gerais (CAO-TS). As prestações analisadas foram referentes ao exercício de 2012, sendo utilizada a amostra não probabilística, por meio de estudo de casos múltiplos. Utilizando os procedimentos internos da Controladoria, realizou-se uma análise do preenchimento do Sistema de Cadastro e Prestação de Contas (SICAP), utilizado os demonstrativos contábeis para coleta de dados e informações. Concluiu-se que os erros e as divergências na prestação de contas das instituições, em sua maioria, referem-se ao preenchimento dos demonstrativos financeiros, não atendendo, muitas vezes, às normas específicas das entidades sem fins lucrativos. Tais erros e divergências se referem também a normas e princípios gerais de Contabilidade, o que compromete a possibilidade de os responsáveis pelas fundações, assim como os Promotores de Justiça e os mantenedores, verificarem a situação econômica, financeira e patrimonial no exercício analisado.
\end{abstract}

Palavras-chave: Entidades de interesse social. Terceiro setor. Fundação de direito privado. SICAP. Prestação de contas.

\section{ABSTRACT}

Efficient accountability is the premise necessary to give greater transparency to any type of business transaction Regarding the institutions of the third sector, this performance is more significant, since their main income sources are associated with an efficient rendering of accounts. In this context, the concern that motivated this research was to answer the following general objective: What are the procedures adopted in the rendering of accounts by private law foundations in Belo Horizonte, Minas Gerais? In methodological terms, this research is classified as a descriptive and bibliographical study. The sample consisted of the accounts from five different purpose foundations at Controladoria do Centro de Apoio Operacional às Alianças Intersetoriais do Ministério Público de Minas Gerais (CAO-TS). The accounts analyzed relate to the financial year of 2012, through a non-probabilistic sample, with a multiple case study. Using the internal procedures from CAO-TS, we made an analysis of the information filling in the Sistema de Cadastro e Prestação de Contas (SICAP), using the financial statements for the collection of data and information. It was concluded that the errors and disagreements in the rendering of accounts of the institutions, for the most part, refer to the completion of the financial statements, often not meeting the specific norms of non-profit entities. These errors and divergences also refer to general accounting standards and principles, which compromises the possibility for those responsible for foundations, as well as the prosecutors and the maintainers, to verify the economic, financial and equity situation in the year under review.

Keywords: Social interest entities. Third sector. Private right foundation. SICAP. Accountability.

Recebido em: 10-10-2016 Aceito em: 16-05-2017

\section{INTRODUÇÃO}

Para compreensão adequada do terceiro setor, é preciso o esclarecimento de que existem três setores de atividades dentro da sociedade: o Estado (primeiro setor); as entidades privadas ou de mercado

\footnotetext{
"Mestre em Economia de Empresas pela Fead/MG. Graduado em Ciências Contábeis pela Pontifícia Universidade Católica de Minas Gerais

Professor da Pontifícia Universidade Católica de Minas Gerais. Mestrando em Educação pela Pontifícia Universidade Católica de Minas Gerais

"Mestrando em Ciências Contábeis pela Universidade Federal de Minas Gerais.
} 
(segundo setor); e as atividades sem fins lucrativos, que se enquadram no terceiro setor (Cunha \& MatiasPereira, 2012; Campos et al., 2014).

O terceiro setor - universo que envolve organizações sem fins lucrativos, organizações voluntárias privadas, fundações e entidades filantrópicas - exerce um importante papel social, econômico e político, especialmente nas sociedades ocidentais, bem como atua de forma relevante para o desenvolvimento de países ainda não considerados desenvolvidos (ANHEIER; SIEBEL, 1990). No âmbito de sua atuação, desenvolve ações em diversas áreas, como saúde, educação, lazer, cidadania, geração de renda e emprego, preservação do meio ambiente e erradicação da pobreza, contribuindo, dessa forma, com a redução das vulnerabilidades sociais (COSTA; VISCONTI, 2001). Portanto, a evolução das organizações e da sociedade como um todo fez surgir setores que auxiliam no suprimento das demandas da sociedade (SILVA; FERNANDES, 2015).

As entidades do terceiro setor possuem a incumbência - legal ou moral - de prestar contas para um público mais amplo do que em comparação às entidades com finalidades de lucro. Enquanto essas últimas possuem como principal enfoque, em seu processo de prestação de contas, informar, em primeiro lugar, seus investidores acerca do desempenho da entidade e sobre a gestão dos recursos confiados, as organizações pertencentes ao terceiro setor necessitam prestar contas de suas atividades e resultados para diversos atores que fornecem recursos a elas, como o Estado, os doadores e os membros da organização que atuam como voluntários (COSTA, 2005).

Em Minas Gerais, nos últimos anos, tem crescido o número de organizações privadas sem fins lucrativos, ou organizações do terceiro setor. Essas fundações possuem finalidades públicas e de interesse social e não visam à distribuição de lucros entre seus instituidores.

Pelo fato de essas entidades se manterem por meio de recursos fornecidos de diversas fontes, a eficiência e a eficácia de redes e processos de prestação de contas confiáveis e transparentes (accountabilty), construídas dentro e fora da organização, podem ser um elemento decisivo para a continuidade das organizações resultantes das relações sociais. Nesse contexto, apresenta-se a importância da contabilidade para a sobrevivência das instituições (ROBERTS; SCAPENS, 1985; NAKAGAWA; RELVAS; DIAS, 2007).

Uma das principais formas de transparência comuns a essas organizações ocorre no processo de tomada de contas, feita anualmente pelo Ministério Público (MP), mais especificamente pela Controladoria do Centro de Apoio Operacional às Alianças Intersetoriais do Ministério Público de Minas Gerais (CAO-TS).

Nesse processo, o MP pode acompanhar e fiscalizar as atividades dessas entidades e, em seguida, tirar conclusões sobre a situação econômica e financeira delas, avaliando ainda se o seu patrimônio está sendo preservado e efetivamente aplicado na consecução dos seus fins.

Mediante o cenário apresentado, o presente artigo buscou responder à seguinte indagação: Quais são os procedimentos adotados na análise das prestações de contas das fundações de direito privado de Belo Horizonte? Portanto, como objetivo geral, buscou-se ainda identificar e demonstrar os procedimentos adotados na análise das prestações de contas dessas fundações.

Para conceituação de entidades de interesse social, terceiro setor e fundações de direito privado, empregou-se o método de pesquisa bibliográfica. Para entendimento e análise da prestação de contas das fundações em estudo, utilizou-se como base o SICAP (Sistema de Cadastro e Prestação de Contas), instrumento de coleta de dados e informações, além dos procedimentos internos utilizados pelo Ministério Público Estadual, agente do Estado encarregado dessa atribuição.

A pesquisa contemplou as prestações de contas enviadas à Controladoria do CAO-TS e utilizou a amostra não probabilística, por meio de estudo de casos múltiplos de cinco fundações de direito privado com finalidades distintas, situadas na capital mineira, Belo Horizonte.

\section{REFERENCIAL TEÓRICO}

As entidades sem fins lucrativos (ESFL) são instituições privadas com propósitos sociais, e seu patrimônio é constituído, mantido e ampliado a partir de contribuições, doações e subvenções e, de modo algum, reverte-se para os seus membros ou mantenedores (OLAK; NASCIMENTO, 2008). O artigo 11 do Decreto-Lei $n^{\circ} 4.657 / 42$ assim define: "As organizações destinadas a fins de interesse coletivo, como as sociedades e as fundações, obedecem à lei do Estado em que se constituírem" (BRASIL, 1942).

Segundo a Resolução no 1.409/12, que aprovou a ITG 2002, do Conselho Federal de Contabilidade (2012), o resultado positivo ou superávit, nas entidades sem fins lucrativos, não é destinado a remunerar os sócios ou acionistas, como nas sociedades empresárias que visam aos ganhos monetários.

$\mathrm{Na}$ década de 1990, com o aparecimento da Comunidade Solidária, criou-se um grupo de trabalho denominado Marco Legal do Terceiro Setor para regulamentar as entidades de interesse social. Enquanto o primeiro setor (o Estado) e o segundo setor (o mercado) já possuíam suas leis e regras estabelecidas, o terceiro setor (as entidades de interesse social) ressentia-se da falta dessa regulamentação. Dessa maneira, o Marco 
Legal envolvia uma legislação societária, uma legislação sobre o trabalho voluntário, relações de trabalho em geral, fiscalização e acompanhamento dos recursos oriundos de incentivos fiscais e da sua destinação, ou seja, evidenciava a transparência da gestão dos recursos nessas entidades. (CFC, 2004).

De acordo com o Manual de Procedimentos Contábeis para Fundações e Entidades de Interesse Social, são características básicas do terceiro setor:

- promoção de ações voltadas para o bem-estar comum da coletividade;

- manutenção de finalidades não lucrativas;

- adoção de personalidade jurídica adequada aos fins sociais (associação ou fundação);

- atividades financiadas por subvenções do Primeiro Setor (governamental) e doações do Segundo Setor (empresarial, de fins econômicos) e de particulares;

- aplicação do resultado das atividades econômicas que porventura exerça nos fins sociais a que se destina;

- desde que cumpra requisitos específicos, é fomentado por renúncia fiscal do Estado (CFC, 2004).

Atualmente no Brasil, a expressão "terceiro setor" vem encontrando maior aceitação para designar o conjunto de iniciativas provenientes da sociedade, voltadas à produção de bens públicos (OLAK; NASCIMENTO, 2008). O terceiro setor, segundo Souza (2001, p.1), é uma terceira via, "subvertendo as relações entre empresas e pessoas, com a valorização do social, pretendendo a prestação de serviços de interesse social sem as limitações do Estado, nem sempre evitáveis, e as ambições do mercado, muitas vezes inaceitáveis". Segundo o autor, esse setor tem sido identificado com o conceito de sociedade civil.

Conforme Silva e Aguiar (2001), o terceiro setor caracteriza-se por ser uma combinação entre as finalidades do primeiro setor e a metodologia do segundo, uma vez que é composto de organizações que objetivam alcançar benefícios tanto coletivos como de natureza privada, sendo um espaço de participação cidadã. As ações nesse espaço são, dessa forma, uma extensão da esfera pública, atividades não executadas pelo Estado, tampouco geridas pelos mercados, por serem caras demais. O cidadão torna-se, assim, um agente ativo da sociedade civil, organizando-a de modo a catalisar o trabalho voluntário em substituição aos serviços oferecidos pelo Estado via taxação compulsória e a transformar em doação a busca por lucro do mercado.

Silva e Aguiar postulam que a definição de terceiro setor mais utilizada e aceita, denominada estrutural/operacional, foi criada por Salamon e Anheier. Segundo os autores, as organizações desse setor apresentam cinco características principais:

- Estruturadas: possuem certo nível de formalização de regras e procedimentos, ou algum grau de organização permanente. São, portanto, excluídas as organizações sociais que não apresentem uma estrutura interna formal;

- Privadas: estas organizações não têm nenhuma relação institucional com governos, embora possam dele receber recursos;

- Não distribuidoras de lucros: nenhum lucro gerado pode ser distribuído entre seus proprietários ou dirigentes. Portanto, o que distingue essas organizações não é o fato de não possuírem "fins lucrativos", e sim, o destino que é dado a estes, quando existem. Eles devem ser dirigidos à realização da missão da instituição;

- Autônomas: possuem os meios para controlar sua própria gestão, não sendo controladas por entidades externas;

- Voluntárias: envolvem um grau significativo de participação voluntária (trabalho não remunerado). A participação de voluntários pode variar entre organizações e de acordo com a natureza da atividade por ela desenvolvida (SALAMON; ANHEIER apud SILVA; AGUIAR, 2001, p. 4).

\subsection{Fundações de direito privado}

O artigo 40 da Lei no 10.406/02 classifica as pessoas jurídicas em direito público interno, direito público externo e direito privado. São pessoas jurídicas de direito público interno: a União; os Estados, o Distrito Federal e os Territórios; os Municípios; as autarquias, inclusive as associações públicas; as demais entidades de caráter público criadas por lei. Já as pessoas jurídicas de direito privado são: as associações; as sociedades; as fundações; as organizações religiosas; os partidos políticos; as empresas individuais de responsabilidade ilimitada (BRASIL, 2002).

Segundo Silva (2013), as fundações de direito privado são constituídas a partir de um patrimônio ou viabilidade econômica, estabelecendo seu funcionamento e organização através de um estatuto, que passa a ser a lei que rege as relações jurídicas envolvidas.

Nunes, citado no Manual de Procedimentos Contábeis para Fundações e Entidades de Interesse Social, define fundação como: 
Uma instituição autônoma, criada por liberalidade privada ou pelo Estado, por meio de escritura pública ou testamento, com personalidade jurídica, patrimônio próprio especificado e fim altruístico, beneficente ou de necessidade, interesse ou utilidade pública ou social, administrada segundo determinações de seus fundadores (NUNES apud CFC, 2004, p. 27).

Olak e Nascimento (2008, p. 16) afirmam que, para a existência de uma fundação, são necessários os seguintes elementos: um instituidor; uma dotação patrimonial de bens livres; um ato de instituição; um estatuto, contendo as regras que irão geri-la e sua estrutura organizacional; aprovação da escritura e dos estatutos pelo representante do Ministério Público que exerce a função de curador de fundações; e registro da escritura pública de instituição e dotação no Cartório de Registro Civil das Pessoas Jurídicas.

Nos artigos de 1.199 a 1.204 da Lei no 5.869 (BRASIL, 1973), estão dispostos os requisitos para a organização das fundações, estabelecendo que o instituidor deverá, ao criar a fundação, elaborar o seu estatuto ou designar quem o faça. Uma vez pronto, o estatuto será submetido à Promotoria de Tutela de Fundações do Ministério Público, que verificará se foram observadas as bases da fundação e se os bens são suficientes ao fim a que ela se destina.

As entidades sem fins lucrativos passam a ter existência legal com sua inscrição no Registro Civil das Pessoas Jurídicas, conforme o artigo 114 da Lei no 6.015 (BRASIL, 1973).

Uma vez atendidos todos os procedimentos de registro, o Cartório de Registro Civil das Pessoas Jurídicas expedirá, em nome da entidade, a certidão de personalidade jurídica, que será a prova da sua existência legal (MELCHOR, 2012).

Atualmente em Minas Gerais, de acordo com o Banco de Dados da Controladoria do Centro de Apoio Operacional às Alianças Intersetoriais do Ministério Público de Minas Gerais (CAO-TS), existem mais de 600 fundações espalhadas por todo o Estado, sendo 144 localizadas na capital. São exemplos dessas entidades a Fundação Pitágoras (Belo Horizonte), a Fundação CEFET-MG (Belo Horizonte), a Fundação Assistencial Viçosense (Viçosa), a Fundação Hospitalar de Montes Claros (Montes Claros), a Fundação Educacional de Lavras (Lavras), entre outras.

\subsection{A prestação de contas das fundações de direito privado de Belo Horizonte junto ao Ministério Público Estadual}

Marcovitch, citado por Olak e Nascimento (2008, p. 21), afirma que, por desempenhar função de interesse público, é esperado que a organização do terceiro setor cultive a transparência quanto aos projetos, resultados obtidos e os recursos alocados. Nesse sentido, a preparação de relatórios de avaliação e a sua disseminação constituem importantes instrumentos de comunicação com a sociedade.

No caso das ESFL, os provedores querem saber se os recursos colocados à disposição dos gestores foram aplicados nos projetos institucionais. Se isso não ocorrer, provavelmente tais entidades terão seus recursos restritos ou até mesmo cortados. Dadas tais características, a relação de accountability é muito forte nessas entidades. Por outro lado, a falta de transparência é, algumas vezes, proposital, no sentido de encobrir escândalos envolvendo alguns gestores inescrupulosos, ou mesmo apenas para usufruir dos benefícios fiscais concedidos a entidades que de filantrópicas só têm o nome.

Por tais razões, cabe ao Ministério Público fiscalizar a prestação de contas das instituições qualificadas como entidade de interesse social. $O$ velamento das fundações e a fiscalização das associações são realizados de acordo com atos normativos dos Ministérios Públicos dos Estados e do Distrito Federal. Ressalta-se que as fundações privadas devem sempre prestar contas ao Ministério Público, anualmente.

O artigo 66 da Lei no 10.406 (BRASIL, 2002) atribui ao Ministério Público dos Estados o velamento pelas fundações e ainda dispõe que, quando as atividades da fundação se estenderem por mais de uma unidade da Federação, cabe ao respectivo Ministério Público Estadual, ou do Distrito Federal, o encargo do velamento das atividades desenvolvidas dentro de sua jurisdição.

Velar pelas fundações significa exercer toda atividade fiscalizadora, a fim de verificar se os órgãos dirigentes realizam proveitosa gerência da fundação, de modo a alcançar, da forma mais completa, a vontade do instituidor.

Como disposto por Olak e Nascimento (2008), o Ministério Público atua de três formas ao velar pelas fundações: no momento da instituição da fundação, através do exame e da decisão quanto aos seus atos constitutivos; durante a existência da fundação, fiscalizando-a; e também analisando a prestação anual de contas dessas entidades.

De acordo com Souza (2001), no artigo "O Ministério Público e o Terceiro Setor", a instituição do MP é essencial à função jurisdicional do Estado, por ter como missão defender a ordem jurídica, o regime democrático e, ainda, os interesses sociais e individuais indisponíveis. Dessa forma, torna-se indispensável para aquelas camadas mais humildes, excluídas ao longo da história no processo econômico-social, em que o terceiro setor se sobrepõe e vem ganhando importância e reconhecimento. 
Em sua atividade de velar pelas fundações, Souza (2001) afirma que o Ministério Público exerce o controle prévio e finalístico. Prévio quando determina que o estatuto, obrigatoriamente, seja apreciado e aprovado por ele, sem o que a entidade não poderá existir validamente; finalístico quando fiscaliza o cumprimento dos objetivos a que se destina a entidade, exercendo o controle externo das suas contas, podendo intervir para adequá-la aos fins propostos pelo instituidor, inclusive agitar a sua extinção. Já a fiscalização das demais entidades de interesse social só será realizada pelo Ministério Público através do controle finalístico.

A Resolução no 126/01 do Ministério Público de Minas Gerais, em seu artigo 18, discorre sobre os deveres desse órgão ao velar pelas fundações:

Art. 18 No velamento das fundações, o respectivo órgão do Ministério Público deverá:

I. exigir que o representante legal da fundação, no ato da aprovação e imediatamente após a inscrição dos atos constitutivos no Cartório de Registro Civil de Pessoas Jurídicas, protocole, na respectiva Promotoria de Justiça, certidão de inteiro teor do registro e instrumentos que comprovem a transferência dos bens que constituíram a entidade;

II. intervir em todos os feitos judiciais ou administrativos em que houver interesse de alguma fundação de direito privado (autora, ré, assistente ou opoente);

III. propor, autorizar ou negar qualquer modificação no estatuto, desde que necessárias ao atendimento do interesse público da fundação, fixando, no caso de aprovação, prazo para que o presidente da entidade protocole, na respectiva Promotoria de Justiça,o registro do estatuto, com a averbação efetuada;

IV. requisitar, anualmente, prestação de contas da entidade;

V. visitar a fundação pelo menos uma vez por ano, ou sempre que entender necessário;

VI. providenciar o preenchimento dos órgãos administrativos da fundação, sempre que a mesma ficar acéfala;

VII. provocar judicialmente a intervenção na administração da fundação, quando fatos levarem à conclusão de má gestão da entidade;

VIII. avaliar e manifestar-se, através de resolução, sobre a necessidade de alienação, permuta ou gravame de bens pertencentes à fundação;

IX. elaborar o estatuto e providenciar o registro da fundação, no caso de instituição por declaração de última vontade ou em razão de omissão dos encarregados;

$X$. requerer em juízo qualquer provimento em favor da fundação, independente da vontade de eventuais administradores ou beneficiários, que, se estiverem adotando atitudes que impeçam ou prejudiquem o regular cumprimento das finalidades do patrimônio personalizado, deverão ser afastados através de medida judicial que garanta a intervenção na administração da entidade;

XI. propor judicialmente a extinção da fundação, exigindo prestação de contas e indicando outra fundação para absorver o patrimônio, sempre que a fundação estiver acéfala, inativa ou não estiver cumprindo suas finalidades; XII. promover, nas hipóteses do inciso anterior, o restabelecimento da entidade, se possível, ou a extinção pela via administrativa que poderá ser feita da forma como se deu a instituição: aprovação dos órgãos superiores de administração, aprovação do Curador de Fundações e averbação no registro civil de pessoas jurídicas;

XIII. adotar outras providências administrativas e judiciais que julgar pertinentes ao exercício de suas atribuições (MINAS GERAIS, 2001).

Os representantes legais das entidades de interesse social têm como obrigação, conforme inciso IV do artigo 18, citado anteriormente, prestar contas anualmente ao Ministério Público do Estado. No caso das fundações de direito privado de Belo Horizonte, as prestações de contas serão feitas através do SICAP (Sistema de Cadastro e Prestação de Contas), para análise e emissão do parecer técnico da real situação econômica e financeira da fundação.

O SICAP é um software desenvolvido para a Promotoria de Tutela de Fundações e Entidades de Interesse Social de Belo Horizonte pela FIPE (Fundação Instituto de Pesquisas Econômicas, de São Paulo). Esse software é obrigatório para que sejam feitas a análise das informações e a elaboração de Atestado de Regularidade por parte do Setor de Controladoria do Centro de Apoio Operacional às Alianças Intersetoriais do Ministério Público de Minas Gerais (CAO-TS).

"O SICAP tem por objetivo, também, o provimento de dados para a elaboração de estudos e estatísticas e a disponibilização de informações econômico-sociais das instituições sem fins lucrativos" (CEFEIS, 2015). De acordo com Melo (2015), O SICAP possibilita à Promotoria das Fundações o efetivo conhecimento dos mais diversos dados financeiros, contábeis, administrativos e sociais da vida dessas entidades.

Desse modo, conforme os artigos de 19 a 24 da Resolução no 126/01 do Ministério Público de Minas Gerais, dentro do período de seis meses que anteceder o término do exercício financeiro das fundações, o órgão do Ministério Público encaminhará cópia do citado programa de computação destinado à coleta de dados informativos, a fim de que estes sejam remetidos posteriormente à Promotoria de Tutela de Fundações da Capital, os quais serão enviados à Controladoria do CAO-TS com os dados informativos e, posteriormente, registrados no Banco de Dados de Fundações (MINAS GERAIS, 2001).

A Controladoria encaminhará ulteriormente aos promotores de justiça - a cujos cargos sejam 
atribuídas as funções judiciais e extrajudiciais do Ministério Público de velar pelas fundações - relatórios técnicos obtidos da análise das informações prestadas por essas entidades, informando sua aprovação ou a ressalva de que pende de aprovação (MINAS GERAIS, 2001).

O setor aprovará ou não as contas, arquivando-se o processo. No caso da não aprovação das contas, tomará as medidas cabíveis que julgar necessárias, tendo como base o parecer técnico obtido da análise dos dados referentes às entidades.

Não prestadas as contas em tempo hábil, o órgão do Ministério Público determinará que a fundação o faça no prazo de trinta dias. As prestações de contas devem ser elaboradas de acordo com a Resolução no 1.409/12 - ITG 2002 - do Conselho Federal de Contabilidade (2012) e devem conter o Relatório de Atividades, Relação Anual de Informações Sociais (RAIS), Parecer de Auditoria Independente e as seguintes Demonstrações Contábeis: Balanço Patrimonial, Demonstração do Superávit ou Déficit, Demonstração das Mutações do Patrimônio Social e Demonstração dos Fluxos de Caixa.

As Demonstrações Contábeis devem ser firmadas por contabilista habilitado pelo representante legal da entidade. Devem ainda ser elaboradas de acordo com os Princípios Fundamentais de Contabilidade e as Normas Brasileiras de Contabilidade aplicáveis à entidade e são obrigatórias para todas as entidades de interesse social.

Esses demonstrativos, conforme o Manual de Procedimentos Contábeis para Fundações de Interesse Social, devem fornecer informações de forma regular e tempestiva; possibilitar o acesso do usuário da informação aos objetivos, à estrutura e às atividades executadas pelas entidades; e possibilitar ao usuário uma apreciação das transações realizadas durante o exercício social das entidades de interesse social, bem como uma posição contábil ao final do exercício contábil (CFC, 2004, p. 81).

"Uma das principais obrigações dos administradores das entidades de interesse social é prestar contas, primeiramente, ao próprio órgão deliberativo da entidade, e, por fim, ao Poder Público" (CFC, 2004, p. 103).

Até o dia 30 de junho do exercício financeiro seguinte, as fundações deverão elaborar a prestação de contas relativa ao ano-base anterior, que deverá ser entregue através de arquivo eletrônico gerado pelo SICAP. Após cada fundação protocolar a entrega na Promotoria de Tutela de Fundações da Capital, uma cópia será enviada ao CAO-TS, para ser gravada no SICAP do Setor de Controladoria e, assim, iniciaremse as análises e a emissão do parecer técnico informando aos promotores responsáveis por essas fundações a real situação econômica e financeira da entidade.

A Controladoria, para análise das prestações de contas, baseia-se no roteiro para elaboração do parecer, formulado pelos analistas do CAO-TS, com base na Resolução CFC no 1.409/12 - ITG 2002 -, para orientar os critérios e procedimentos específicos de avaliação, de reconhecimento das transações e variações patrimoniais, de estruturação das demonstrações contábeis e as informações mínimas a serem divulgadas em notas explicativas das entidades sem finalidade de lucros.

Essa Interpretação Técnica revoga as seguintes normas: NBC T 10.19 - Entidades Sem Finalidade de Lucros; NBC T 10.4 - Fundações; e NBC T 10.18 - Entidades Sindicais e Associações de Classe.

$\mathrm{Na}$ análise, verificam-se diversas informações e demonstrativos, tais como o estatuto, a RAIS, os demonstrativos contábeis, as fontes de recursos, o parecer da auditoria externa, o relatório das atividades, além de cálculos para o conhecimento da situação de liquidez e endividamento no período analisado.

\subsection{Controladoria do Centro de Apoio Operacional às Alianças Intersetoriais do Ministério Público de Minas Gerais (CAO-TS)}

As fundações de direito privado de Belo Horizonte devem prestar contas anualmente ao Ministério Público Estadual, mais especificamente à Controladoria do Centro de Apoio Operacional às Alianças Intersetoriais do Ministério Público de Minas Gerais (CAO-TS).

O Ministério Público é uma instituição pública autônoma, a quem a Constituição Federal atribuiu a incumbência de defender a ordem jurídica, o regime democrático e os interesses sociais e individuais indisponíveis. Os integrantes do Ministério Público Estadual são os Promotores de Justiça (que atuam no primeiro grau de jurisdição) e os Procuradores de Justiça (que atuam no segundo grau de jurisdição, junto aos tribunais), auxiliados por servidores, assistentes jurídicos e estagiários, todos com ingresso na instituição mediante concurso público. Além da área criminal, o Ministério Público atua na defesa do patrimônio público e social, do meio ambiente, da habitação e urbanismo, da infância e da juventude, dos idosos, das pessoas com deficiência, dos direitos humanos, da saúde pública, da educação, do consumidor e, ainda, em falências e fundações, entre outros (SÃO PAULO, 2015).

O CAO-TS, anteriormente conhecido como Centro de Apoio Operacional ao Terceiro Setor, foi oficialmente instituído em 06 de maio de 2004, conforme a Resolução ㄲo39/2004, tendo sido idealizado e coordenado pelo Procurador de Justiça Tomáz de Aquino Resende, possuindo como principais atribuições: auxiliar o funcionamento administrativo das Promotorias de Tutela de Fundações e Entidades de Interesse 
Social de Minas Gerais; propor melhorias na legislação; produzir e difundir informações e conhecimentos sobre o Terceiro Setor; estimular a capacitação de organizações sem fins lucrativos; oferecer contribuição aos programas sociais em desenvolvimento em Minas Gerais, agindo como órgão centralizador das informações, bancos de dados e convergências de propósitos e projetos existentes entre as inúmeras entidades que compõem o Estado.

Esse centro tem como objetivo estratégico velar pelo patrimônio social das entidades de interesse social sem fins lucrativos e promover a articulação entre os três setores, implementando, através de parcerias efetivas, ações para o desenvolvimento social e ambiental da coletividade. Como objetivos operacionais, destacam-se: prestar apoio às promotorias especializadas, conforme competências previstas na Resolução no 64; zelar pelas organizações sem fins lucrativos que prestem serviços de interesse público, especialmente aquelas que utilizam recursos públicos e doações de pessoas físicas para execução dessas atividades; e ainda determinar que seja cumprida a prestação de contas de todas as fundações de direito privado do Estado de Minas Gerais (MINAS GERAIS, 2015).

\subsection{Estudos anteriores}

Neste tópico, apresentam-se alguns estudos que estão diretamente ligados e têm grande relevância para a presente pesquisa. O estudo desenvolvido por Portulhak et al. (2015) teve como objetivo verificar se existe uma relação entre a prática de prestação de contas e o comportamento de indivíduos no papel de doadores. Para isso, foi realizado um levantamento junto a doadores individuais atuais e anteriores que moram na cidade de Curitiba e Região Metropolitana, tendo sido obtidas 277 respostas de indivíduos que foram divididos em oito grupos distintos. A análise descritiva dos dados, baseada em 17 hipóteses de pesquisa, foi complementada com a aplicação de testes estatísticos, como $\mathrm{U}$, de Mann-Whitney, e $\mathrm{H}$, de Kruskal-Wallis. Os resultados indicaram que, em geral, há uma relação positiva entre a prestação de contas realizada por entidades do terceiro setor e o comportamento de doação de indivíduos, o que ocorre de forma mais significativa no comportamento de manter, aumentar ou retomar doações.

Outro estudo de Portulhak et al. (2017) teve como objetivo geral investigar a relação entre a qualidade da prestação de contas realizada por entidades do terceiro setor e o comportamento de doadores individuais. A qualidade da prestação de contas foi medida conforme Trussel e Parsons (2008), que a indicam como um constructo composto por eficiência, estabilidade, quantidade e reputação. Buscou-se verificar se determinado eixo de qualidade da prestação de contas possui maior peso na decisão do doador individual, bem como se a forma de recebimento da prestação de contas e a disposição do doador individual em buscá-la possui influência na sua decisão ao prover recursos. Os resultados indicaram que, de modo geral, os doadores atuais conseguem perceber maior qualidade nas prestações de contas do que os antigos doadores. Além disso, tanto os doadores atuais quanto os antigos, que não recebem ou não receberam prestação de contas, percebem mais qualidade do que os que já receberam ou recebem essa informação.

Já o estudo de Zittei, Politelo e Scarpine (2016) objetivou identificar o nível de evidenciação contábil das entidades do terceiro setor participantes do projeto de Desenvolvimento de Princípios de Transparência e Prestação de Contas em Organizações da Sociedade Civil - BID. A população da pesquisa foi composta por 76 entidades, e a amostra compreendeu 15 entidades que divulgaram sua prestação de contas em seus sítios. Para coleta dos dados foi elaborado um checklist composto por 63 itens dos quais 53 eram baseados no Pronunciamento Técnico CPC 26 e 10 itens baseados na norma NBC T 10.19. Os resultados da pesquisa evidenciaram que as entidades enfatizam a evidenciação das informações qualitativas e apresentam informações quantitativas de maneira sintética em sua maioria. Conclui-se que o nível médio de evidenciação das entidades participantes do projeto foi de $27 \%$, percebendo, assim, a necessidade de estudos para apresentar as reais necessidades de evidenciação e fomentar normas específicas para o setor.

\section{PROCEDIMENTOS METODOLÓGICOS}

A utilização e a especificação dos métodos utilizados para o desenvolvimento de pesquisas são essenciais, pois atribuem caráter científico aos estudos, distinguindo-os das demais formas de conhecimento. As pesquisas acadêmicas classificam-se quanto aos objetivos, aos procedimentos e à abordagem do problema (Malhotra, 2006). A metodologia é o emprego do conjunto de métodos, procedimentos e técnicas que cada ciência em particular põe em ação para alcançar os seus objetivos. A colaboração entre demonstração lógica e experimentação, a interação entre ciência pura e tecnologia é uma característica do espírito científico contemporâneo (Matias-Pereira, 2012).

Quanto aos fins, esta pesquisa se caracteriza como descritiva, cujo objetivo primordial é a descrição das características de determinada população ou fenômeno, ou então o estabelecimento de relações entre as variáveis. As finalidades são observar, registrar e analisar os fenômenos ou sistemas técnicos sem, entretanto, entrar no mérito dos conteúdos (Gil, 2009). Esse método exige do investigador uma série de 
informações sobre o que este deseja pesquisar. Esse tipo de estudo pretende descrever os fatos e fenômenos de determinada realidade, no caso a realidade das entidades do terceiro setor sediadas no Estado de Minas Gerais e suas respectivas prestações de contas (Triviños, 1987). Os procedimentos técnicos utilizados para o desenvolvimento desta pesquisa foram seguidos à luz de uma ampla pesquisa bibliográfica elaborada a partir de material publicado. Esta pesquisa foi feita a partir do levantamento dos referenciais teóricos já analisados e publicados por meios escritos e eletrônicos, como livros, artigos científicos e páginas da web.

Quanto à abordagem do problema e ao tratamento dos dados, este estudo se enquadra como pesquisa predominantemente qualitativa, pois procurará compreender os dados no contexto em que foram produzidos. Raupp e Beuren (2004, p. 92) explicam que "na pesquisa qualitativa concebem-se análises mais profundas em relação ao fenômeno estudado". O estudo foi realizado por meio de multicasos que possibilitam levantar evidências relevantes e de maior confiabilidade se comparados aos estudos de casos únicos (Yin, 2001). Segundo Boyd e Westfall (1987), o estudo de multicasos tem se mostrado conveniente na identificação de três fatores: "fatores comuns a todos os casos no grupo escolhido; fatores não comuns a todos, mas apenas a alguns subgrupos; fatores únicos em caso específico" (Boyd \& Westfall, 1987, p. 73). A coleta e o tratamento de dados foram realizados de maneira não probabilística acidental, destacando-se, aqui, "aquelas selecionadas por acessibilidade e tipicidade" (Vergara, 2015, p. 25). A amostra é "constituída pela seleção de elementos que o pesquisador considere representativos do universo alvo" (Vergara, 2015, p. 32).

Realizou-se a análise, via SICAP, das prestações de contas do exercício de 2012 de cinco fundações de direito privado, cujos nomes foram omitidos para preservar a identidade dessas entidades, as quais possuem diferentes finalidades: saúde, cultura, desenvolvimento e habitação, educação e pesquisa, e assistência social. O motivo da seleção dessas cinco amostras foi devido à acessibilidade. Assim, a amostra configura-se como não probabilística e formada pelo critério de acessibilidade. Conforme Beuren (2008), esse é um método de coleta de dados feito por meio da interrogação direta das pessoas cujo comportamento se deseja conhecer. Para análise desses dados, foi aplicada a análise técnica de conteúdos, a fim de aproveitar as principais informações coletadas na técnica de levantamento de dados.

Como critério na prestação de contas, foram avaliados os seguintes itens:

- Estatuto e missão;

- Relação Anual de informações Sociais ( RAIS);

- Demonstrações Financeiras.

Foram atribuídas as seguintes avaliações:

a) Sem preenchimento: quando não forem encontradas informações necessárias;

b) Insatisfatórias: quando não houve atendimento às necessidades de informações;

c) Correções: quando as informações contiverem alguma irregularidade em seu preenchimento;

d) Satisfatório: quando apresentar o mínimo necessário.

\section{ESTUDO DE CASOS MÚLTIPLOS}

\subsection{Análise das principais informações (estatuto e missão, RAIS e Demonstrações Financeiras)}

Após análise das prestações de contas das cinco fundações através dos procedimentos utilizados pelos analistas da Controladoria do CAO-TS, verificou-se que, mesmo tendo sido elaboradas por contadores, com algumas das entidades tendo suas contas examinadas por auditores externos independentes, há erros e divergências em relação ao preenchimento dos demonstrativos financeiros e quanto ao preenchimento das abas do SICAP.

Os critérios e procedimentos estabelecidos pela Resolução 1.409/12 - ITG 2002 - para as demonstrações financeiras dessas organizações sem fins lucrativos não estão sendo adotados no seu todo, gerando ressalvas em todos os demonstrativos analisados.

No demonstrativo "Ativo", conforme estabelecido na Resolução citada, deve-se constituir provisão em montante suficiente para cobrir as perdas esperadas sobre créditos a receber, o que não é feito na maioria das entidades, exceto as Fundações 4 e 5, que contabilizaram valores para a "Provisão de Créditos de Liquidação Duvidosa". No "Ativo", observa-se também o não lançamento da "Amortização e Depreciação Acumulada" para as fundações 1 e 4, itens que devem ser corrigidos, visto que são contas que vão reduzir 0 ativo total no período analisado.

Em relação ao demonstrativo "Passivo", o valor do Superávit ou Déficit acumulado deve ser incorporado ao patrimônio social, apontamento feito para todas as fundações, o que revela mais uma vez o não cumprimento da referida Resolução pela maioria das entidades em estudo. Além disso, o valor da rubrica "Superávit ou déficit do exercício" encontra-se zerado para a Fundação 1, enquanto para a entidade 4, há saldos divergentes do demonstrativo de Superávit ou Déficit. 
Quanto aos demonstrativos "Receitas e Despesas", os únicos apontamentos feitos para posteriores esclarecimentos referem-se a uma receita decorrente da venda de Ativo Permanente pela fundação 4, sendo preciso informar se houve autorização pelo Ministério Público. Para a Fundação 5 , o valor do demonstrativo Despesas não confere com o demonstrativo de Superávit ou Déficit.

No demonstrativo "Fontes de Recursos da Instituição", o valor informado não confere com o demonstrativo de Receitas, um dos erros encontrados em quase todas as entidades, exceto para a Fundação 5.

O preenchimento da demonstração "Fluxo de Caixa" é obrigatório e foi feito pela maioria das fundações de maneira satisfatória, sendo que a única que entregou a prestação de contas sem o preenchimento adequado foi a Fundação 2.

Em se tratando do demonstrativo "Composição Analítica das Contas do Ativo Permanente", tal informação não foi preenchida pela Fundação 1 e, para as Fundações 3 e 5, houve divergências nas rubricas do imobilizado e intangível em relação ao demonstrativo "Ativo". No caso da Fundação 4, pede-se o esclarecimento de reduções no "Ativo Permanente", já que não foram encontradas informações esclarecedoras nas notas explicativas, modo que tais reduções podem ter como motivo a venda desses itens, o que só pode acontecer mediante autorização do MP, como abordado anteriormente.

No demonstrativo "Mutações do Patrimônio", o valor do saldo final do exercício de 2011 não confere com o valor do saldo inicial do exercício de 2012, divergência apontada nas prestações de contas das Fundações 1, 2 e 4 . No caso da Fundação 5, são solicitados esclarecimentos em notas explicativas quanto ao valor alocado na rubrica "Aumento do fundo social".

Outro ponto a ser analisado, e que se refere aos demonstrativos financeiros, são as inconsistências de valores entre os demonstrativos "Passivo", "Mutações do Patrimônio Líquido" e "Superávit ou Déficit". No caso das Fundações 4 e 5, a diferença entre o exercício atual e o anterior, encontrada no demonstrativo Passivo, não confere com o resultado apurado no demonstrativo "Superávit ou Déficit". Outro erro apontado na Fundação 4 refere-se ao fato de o saldo final do demonstrativo "Mutações do Patrimônio Líquido" ser divergente em relação ao "Patrimônio Líquido no Passivo".

Por fim, as notas explicativas devem ser elaboradas de acordo com a Resolução 1.409/12 para as Fundações 1,2 e 3.

Ao tratar do preenchimento das abas do programa utilizado, verificam-se poucos erros cometidos pelas fundações analisadas no estudo. $O$ estatuto, as informações dos demonstrativos financeiros e 0 relatório das atividades não foram preenchidos satisfatoriamente apenas pela Fundação 2, além do relatório das atividades pela Fundação 1.

Outros pontos importantes a se observar nas prestações de contas referem-se aos financiamentos com recursos do orçamento público, à Relação Anual de informações Sociais (RAIS) e ao parecer da auditoria externa.

Em relação aos financiamentos com recursos do orçamento público, somente houve apontamentos para as Fundações 1 e 4: no caso da Fundação 1, quanto à falta de informação do registro do órgão, data $e$ valor da subvenção que a entidade informou receber; no caso da Fundação 4, quanto aos valores de Convênios Públicos registrados no Ativo, que divergem da mesma rubrica do Passivo, contabilização equivocada que compromete os índices de Liquidez Corrente, Geral e Endividamento, e, por sua vez, a análise da situação financeira da entidade.

O parecer da auditoria externa, naquelas fundações que possuem suas contas auditadas, apresentou "Opinião com ressalva" apenas na Fundação 4, como apontamento, exigindo da entidade a medida tomada para sanar tal irregularidade.

Cabe destacar as observações referentes à RAIS, visto que nas Fundações 1, 3 e 4 foi constatado que na relação encontram-se conselheiros da entidade, fato que deve ser esclarecido e acompanhado pelos Promotores de Justiça, uma vez que os responsáveis pelas fundações não devem receber nenhum tipo de remuneração, exceto quando exercem outros cargos na fundação.

Por meio da análise feita pelo MP, também é observada a situação financeira e econômica das entidades através dos índices de solvência, endividamento geral e imobilização do patrimônio líquido, bem como por intermédio do resultado apurado no período analisado.

Com a análise das prestações de contas das fundações que fizeram parte da amostra, é possível perceber que, apesar de serem encontrados erros quanto ao preenchimento das abas do SICAP, a grande parte dos apontamentos feitos pela Controladoria do CAO-TS refere-se ao preenchimento dos demonstrativos financeiros.

É importante salientar que com a análise da RAIS, do demonstrativo de Composição Analítica das Contas do Ativo Permanente, do estatuto e do relatório de atividades é que o MP cumpre com um dos seus principais objetivos, o de velar pelas fundações, verificando se algum dirigente está recebendo algum tipo de remuneração, se houve alguma venda do imobilizado sem autorização e, ainda, se as atividades realizadas estão de acordo com as finalidades expostas no estatuto. 
A partir da análise, também é possível verificar, através dos resultados apurados, a capacidade de gestão econômica, financeira e patrimonial no período analisado, o que é fundamental para a manutenção das atividades das fundações para os próximos exercícios.

\subsection{Resumo dos itens}

O Quadro 1 apresentado a seguir sintetiza os achados desta pesquisa. Nas linhas, encontram-se as fundações e, nas colunas, os itens analisados nos procedimentos adotados pela Controladoria do Ministério Público do Estado, conforme listados anteriormente. Os erros e divergências detectados serão apontados no parecer, bem como a situação econômica e financeira da entidade no exercício analisado.

QUADRO 1 - Análise das informações das entidades

\begin{tabular}{|l|l|l|l|}
\hline Entidades & Estatuto e missão & RAIS & Demonstrações financeiras \\
\hline 1 & Satisfatório & Correções & Insatisfatórias \\
\hline 2 & Sem preenchimento & Satisfatório & Insatisfatórias \\
\hline 3 & Satisfatório & Correções & Insatisfatórias \\
\hline 4 & Satisfatório & Correções & Insatisfatórias \\
\hline 5 & Satisfatório & Satisfatório & Insatisfatórias \\
\hline
\end{tabular}

\section{CONCLUSÃO}

As organizações do terceiro setor, composto pelas entidades de interesse social, vêm ganhando destaque e evidência atualmente, uma vez que auxiliam a administração pública no atendimento às inúmeras demandas sociais que já se tornaram impossíveis de serem atendidas pelo setor governamental. Vale ressaltar a autonomia e a independência do terceiro setor em relação ao primeiro (o Estado) e ao segundo (as empresas), inclusive em relação ao volume de recursos financeiros que mobiliza e no número de empregos surgidos com as iniciativas advindas desse campo.

Diante disso, por terem função de interesse público, espera-se que tais organizações comprovem a correta utilização de seus direitos e benefícios legais e, também, a transparência quanto aos seus resultados e atos constitutivos, o que as obriga à prestação anual de contas ao Ministério Público Estadual, o qual tem a incumbência de velar pelas práticas dessas entidades.

$\mathrm{Na}$ presente análise, foram verificados todos os demonstrativos contábeis e as abas preenchidas no SICAP quanto ao atendimento aos procedimentos exigidos dessas fundações, conforme o roteiro utilizado para elaboração do parecer que é usado na análise de todas as fundações da capital mineira, independentemente da finalidade a que cada uma se propõe.

No estudo proposto, foram analisadas cinco fundações de finalidades distintas, escolhidas por acessibilidade, nas quais é possível verificar que, apesar de haver erros quanto ao preenchimento de abas do SICAP, a maior parte dos apontamentos se refere aos demonstrativos contábeis. Estes são elaborados por contadores e passíveis de auditoria externa, mas em sua preparação não atendem a todos os itens constantes na norma.

Cabe salientar que, na maioria dos casos, essas entidades contratam profissionais contábeis terceirizados para a realização do trabalho, profissionais que não participam direta e diariamente das atividades das fundações e que nem sempre são os mesmos a realizar a tarefa a cada exercício, fato que pode ser prejudicial à elaboração dos demonstrativos contábeis, já que não há uma continuidade de serviços. Além disso, há profissionais que não estão aptos e nem atualizados em relação às normas específicas para as entidades sem fins lucrativos.

Mediante essas ponderações, é possível verificar erros em relação à contabilidade em geral, não sendo observadas normas e princípios básicos da Contabilidade, fato que pode comprometer a análise financeira da entidade.

Por meio dos procedimentos adotados pelo MP, além dos erros e divergências em relação às normas contábeis, é possível analisar se houve alguma baixa e como foi investido o patrimônio fundacional, se algum dirigente está sendo remunerado e, ainda, se o fim a que se destina a fundação está sendo observado. Além disso, é demonstrada, através dos índices calculados, a performance da instituição no período em análise.

É importante destacar que, por meio do parecer elaborado pelo CAO-TS quanto às informações abordadas neste estudo, os promotores responsáveis pelas fundações e os mantenedores das instituições têm conhecimento da situação financeira e econômica da entidade.

Por fim, visto o alcance que a análise das prestações de contas dessas entidades pode alcançar através dos procedimentos utilizados pelo MP, cabe avaliar se um acompanhamento mais efetivo por parte desse órgão, através de visitas periódicas, poderá demonstrar um contato mais direto e um maior controle 
em relação à gestão dessas entidades.

Um maior controle por parte do Ministério Público nos aspectos financeiros e econômicos contribui com a redução de erros e divergências encontrados na utilização do sistema e, principalmente, em relação aos demonstrativos contábeis e quanto à alocação adequada dos recursos.

\section{REFERÊNCIAS}

ANHEIER, Helmut K.; SEIBEL, Wolfgang. The third sector: comparative studies of nonprofit organizations. Berlim: Walter de Gruyter, 1990.

BEUREN, Ilse Maria et al. Elaborar trabalhos monográficos em contabilidade: teoria e prática. São Paulo: Atlas, 2008.

BOYD, H. W.; WESTFALL, R. (1987). Pesquisa mercadológica: texto e casos. 7. ed. Rio de Janeiro: FGV.

BRASIL. Decreto-Lei no 4.657, de 4 de setembro de 1942. Lei de Introdução às normas do Direito Brasileiro. Diário Oficial da União. Rio de Janeiro, 4 de setembro de 1942. Disponível em: <http://www.planalto.gov.br/ccivil 03/decretolei/Del4657.htm>. Acesso em: 28 jul. 2015.

BRASIL. Lei no 5.869, de 11 de janeiro de 1973. Institui o Código de Processo Civil. Diário Oficial da União. Brasília, 11 de janeiro de 1973. Disponível em:<http://legis.senado.gov.br/legislacao/ListaTextoIntegral.action?id=75584>. Acesso em: 28 jul. 2015.

BRASIL. Lei no 6.015, de 31 de dezembro de 1973. Dispõe sobre os registros públicos, e dá outras providências. Diário Oficial da União. Brasília, 31 de dezembro de 1973. Disponível em: <http://www.planalto.gov.br/ccivil 03/leis/l6015.htm>. Acesso em: 28 jul. 2015.

BRASIL. Lei no 10.406, de 10 de janeiro de 2002. Institui o Código Civil. Diário Oficial da União. Brasília, 10 de janeiro de 2002. Disponível em: <http://www.planalto.gov.br/ccivil 03/leis/2002/110406.htm>. Acesso em: 28 jul. 2015.

CAMPOS, G. M.; MOREIRA, R. de L.; SCALZER, R. S. Financial reporting: reflection on transparency in the third sector. Sociedade, contabilidade e gestão, v.9, n.3, p.130-142, 2014.

CEFEIS. Centro de Estudos de Fundações e Entidades de Interesse Social. O que é o SICAP?. Jul. 2015. Disponível em: <http://www.fundata.org.br/Oqueeosicap.htm>. Acesso em: 28 jul. 2015.

COLLINS, J.; HUSSEY, R.. Pesquisa em administração. Tradução de Lucia Simonini. Porto Alegre: Bookman, 2005.

COSTA, Daniela Pais. Prestação de contas. In: SZAZI, Eduardo (Org.). Terceiro setor: temas polêmicos. São Paulo: Petrópolis, 2005. p. 13-44.

COSTA, Cláudia Soares; VISCONTI, Gabriel Rangel. Terceiro setor e desenvolvimento social. AS/GESET Relato Setorial $n^{\circ}$ 3, junho, 2001.

CUNHA J. H. da C.; MATIAS-PEREIRA, J. Captação de recursos no terceiro setor: fatores estratégicos para divulgação de informações. Revista Contemporânea de Contabilidade, v. 9, n.18, p. 83-102, 2012.

CFC. Conselho Federal De Contabilidade. Contextualização histórica. In: CFC. Conselho Federal de Contabilidade. Manual de Procedimentos Contábeis para Fundações e Entidades de Interesse Social. Brasília: CFC, 2004.

CFC. Conselho Federal De Contabilidade. Resolução CFC no1.409/12. Aprova a ITG 2002 - Entidade sem finalidade de lucro. Brasília, 21 de setembro de 2012. Disponível em: $<$ http://www.crcsp.org.br/portal novo/legislacao contabil/resolucoes/Res1409.htm>. Acesso em: 28 jul. 2015.

DEVECHI, Catia Piccolo; TREVISAN, Amarildo. Sobre a proximidade do senso comum das pesquisas qualitativas em educação: positividade ou simples decadência? Revista Brasileira de Educação, v. 15, n. 43, p. 148-201, 2010. Disponível em: <http://www.scielo.br/pdf/rbedu/v15n43/a10v15n43.pdf>. Acesso em: 25 fev. 2017.

GIL, A. C. Como elaborar projetos de pesquisa. 4. ed. São Paulo: Atlas, 2009.

MALHOTRA, N. K. Pesquisas de marketing: uma orientação aplicada. Tradução de Laura Bocco. 4.ed. Porto Alegre: Bookman, 2006.

MATIAS-PEREIRA, J. Manual de metodologia da pesquisa científica. 3. ed. São Paulo: Atlas, 2012.

MELCHOR, Paulo. Associação e fundação. Sebrae-SP, São Paulo, 04 de outubro, 2012. Disponível em: $<$ http://www.sebraesp.com.br/index.php/166-produtos-online/legislacao/publicacoes/artigos/6028-associacao-efundacao $>$. Acesso em: 28 jul. 2015.

MELO, Tarcísio Farias de. Fiscalização das contas das fundações pelo Ministério Público. Escola Superior do Ministério Público do Ceará. 28 de julho de 2015. Disponível em:<http://www.mp.ce.gov.br/esmp/publicacoes/ed12010/artigos/5FISCA_Contas.pdf>. Acesso em: 28 jul. 2015.

MINAS GERAIS. Ministério Público. Terceiro Setor - CAO-TS. Portal MPMG, março de 2015. Disponível em: <http://www-antigo.mpmg.mp.br/portal/public/interno/arquivo/id/3164>. Acesso em: 20 mar. 2015.

MINAS GERAIS. Ministério Público. Resolução o126/01. Estabelece normas para a atuação das Promotorias de Tutela das Fundações do Estado de Minas Gerais, e dá outras providências. Belo Horizonte, 26 de dezembro de 2001. Disponível em: <http://www.funepu.com.br/site/images/legislacao/EDlfunepu100701074836.pdf>. Acesso em: 28 jul. 2015. 
MINAS GERAIS. Ministério Público. Procuradoria-Geral de Justiça. Resolução PGJ no 27. Cria, no âmbito do Ministério Público do Estado de Minas Gerais, o Banco de Dados de Fundações, normatiza e padroniza a forma de prestação de contas anual das Fundações situadas em Minas Gerais no âmbito do Ministério Público e dá outras providências. Belo Horizonte, 21 de junho de $2001 . \quad$ Disponível em: <http://www.fundata.org.br/Legislacao MP/LegMP/Minas\%20Gerais/res002701210601MG.pdf>. Acesso em: 28 jul. 2015.

NAKAGAWA, Masayuki; RELVAS, Tania Regina Sordi; DIAS, José Maria, Filho. Accountability: a razão de ser da contabilidade. Revista de Educação e Pesquisa em Contabilidade, v. 1, n. 3, p. 83-100, 2007.

OLAK, Arnaldo Paulo; NASCIMENTO, Diogo Toledo do. Identidade e Caracterização das Entidades sem Fins Lucrativos no Brasil. In: OLAK, Arnaldo Paulo; NASCIMENTO, Diogo Toledo do. Contabilidade para entidades sem fins lucrativos (Terceiro Setor). São Paulo: Atlas, 2008.

PORTULHAK, H.; DELAY, A. J.; PACHECO, V. Prestação de Contas por Entidades do Terceiro Setor e seus Impactos na Obtenção de Recursos: um Olhar Sobre o Comportamento dos Doadores Individuais. Pensar Contábil, v. 17, n. 64, p. 39-47, 2015.

PORTULHAK, H.; VAZ, P. V. C.; DELAY, A. J.; PACHECO, V. A qualidade da prestação de contas das entidades do Terceiro Setor: Uma análise a partir de sua relação com o comportamento dos doadores individuais. Enfoque Reflexão Contábil, v. 36, n. 1, p. 45-63, 2017.

PUC MINAS. Pontifícia Universidade Católica De Minas Gerais. Pró-Reitoria de Graduação. Sistema de Bibliotecas. Padrão PUC Minas de normalização: normas da ABNT para apresentação de teses, dissertações, monografias e trabalhos acadêmicos. 9. ed. rev. ampl. atual. Belo Horizonte: PUC Minas, 2012. Disponível em: $<$ http://www.pucminas.br/biblioteca>. Acesso em: 28 jul. 2015.

RAUPP, F. M.; BEUREN, I. M. Metodologia da pesquisa aplicável às ciências sociais. In: BEUREN, I. M. (Org.). Como elaborar trabalhos monográficos em contabilidade. São Paulo, Atlas, 2004.

ROBERTS, John; SCAPENS, Robert. Accounting systems and systems of accountability - understanding accounting practices in their organizational contexts. Accounting, Organizations, and Society, v. 10, n. 4, p. 443-456, 1985.

SÃO PAULO. Ministério Público. O que é o Ministério Público. 28 de julho de 2015. Disponível em:<http://www.mp.sp.gov.br/portal/page/portal/atribuicoes/o_que_e_o_MP>. Acesso em: 28 jul. 2015.

SILVA, Arcênio Rodrigues da. Fundação de direito privado: Instituição, dotação e estatutos sociais. Âmbito Jurídico, 28 de julho de 2015.2 Disponível em: juridico.com.br/site/index.php?n link=revista artigos leitura\&artigo id=2837>. Acesso em: 28 jul. 2015.

SILVA, Eduardo Marcondes Filinto da; AGUIAR, Marianne Thamm de. Terceiro Setor - Buscando uma conceituação. Cadernos Fundata, setembro de 2001. Disponível em:<http://www.fundata.org.br/Artigos\%20-\%20Cefeis/06\%20\%20TERCEIRO\%20SETOR\%20-\%20BUSCANDO\%20UMA\%20CONCEITUA\%C3\%87\%C3\%830.pdf>. Acesso em: 28 jul. 2015.

SILVA, L. F.; FERNANDES, K. R. As Redes de Relações Interorganizacionais para Prestar os Serviços do Terceiro Setor. Reuna, v. 20, n. 1, p. 45-72, 2015.

SOUZA, Celso Jerônimo de. O Ministério Público e o Terceiro Setor. Cadernos Fundata, Pernambuco, 2001. Disponíve em: $<$ http://www.fundata.org.br/Artigos\%20-\%20Cefeis/14\%20\%200\%20MINIST\%C3\%89RIO\%20P\%C3\%9ABLICO\%20E\%200\%20TERCEIRO\%20SETOR.pdf>. Acesso em: 28 jul. 2015.

TRIVIÑOS, A. N. S. Introdução à pesquisa em ciências sociais: a pesquisa qualitativa em educação: o positivismo, a fenomenologia, o marxismo. São Paulo: Atlas, 1987.

VERGARA, S. C. (2015). Projetos e relatórios de pesquisa em administração. 15. ed. São Paulo: Atlas, 2015.

ZITTEI, M. V. M.; POLITELO, L.; SCARPIN, J. E. Nível de Evidenciação Contábil de Organizações do Terceiro Setor. Administração Pública e Gestão Social, v. 8, n. 2, p. 85-94, 2016.

YIN, R. K. Estudo de caso: planejamento e método. Tradução de D. Grassi. 2. ed. Porto Alegre: Bookman, 2001. 